\title{
COMPARATIVE STUDY OF MICROLEAKAGE AND SHEAR BOND STRENGTH BETWEEN BULK FILL AND SELF ADHESIVE FLOWABLE COMPOSITE RESINS
}

\author{
Mohamed H. Abdelrahman ${ }^{l} B D S$, Elsayed M. Mahmoud ${ }^{2} P h D$, Mona M. Ghoneim ${ }^{3} P h D$, \\ Adel A. Kammar ${ }^{4} P h D$
}

\begin{abstract} for time saving and better adaptation.

OBJECTIVES: was to compare the microleakage and shear bond strength of Self-adhesive\& Bulk fill flowable composite resins. strength was measured using universal testing machine. flow. microleakage but higher shear bond strength than Vertise flow.

KEYWORDS: Flowable bulks fill composite, Vertise flow, microleakage, shear bond strength.

\footnotetext{
1- Instructor at Conservative Dentistry Department, Faculty of Dentistry, Alexandria University, Alexandria, Egypt.

2- Professor of Operative Dentistry, Faculty of Dentistry, Alexandria University, Alexandria, Egypt.

3- Assistant Professor of Operative Dentistry, Faculty of Dentistry, Alexandria University, Alexandria, Egypt.

4- Professor of Dental Material, Faculty of Dentistry, Alexandria University. Alexandria, Egypt.
}

INTRODUCTION: Advances in flowable composites including self-adhesive and bulk fill flowable composite resin have been introduced

MATERIAL AND METHODS: A total of forty non carious extracted human molars were selected for this study. For microleakage test, twenty Class V cavities were prepared on labial surface. Teeth were divided into 2 groups $(n=10)$, Group I: was treated with self-adhesive flowable composite, Group II: was treated with one step self-etch adhesive system with bulk fill flowable composite. Microleakage scores were evaluated on the occlusal and cervical walls and data was analyzed statistically. For Shear bond strength test, twenty molars were embedded in acrylic resin inside plastic molds; the occlusal portion of each tooth was removed. To standardize the bonding area, cylindrical shaped plastic matrices with $4 \mathrm{~mm}$ internal diameter and $3 \mathrm{~mm}$ height were used. Specimens were divided into 2 groups ( $\mathrm{n}=10$ ), Group I: was treated with selfadhesive flowable composite, Group II: was treated with one step self-etch adhesive system with bulk fill flowable composite. Shear bond

RESULTS:The cervical margins showed a non-significant higher mean of microleakage scores than the occlusal margins in the two studied restorative materials. Filtek flowable bulk fill composite showed significantly higher mean of microleakage scores than Vertise flow at both the cervical and occlusal margins. Filtek flowable bulk fill composite showed a significantly higher mean of shear bond strength than Vertise

CONCLUSIONS: All of the restorative materials used were unable to prevent microleakage. Filtek flowable bulk fill composite showed more

\section{INTRODUCTION}

Modern cosmetic and reconstructive dentistry is now difficult to imagine without the use of flowable composite materials. Since its market launch in late 1996, these materials have become the material of choice for fillings that are not exposed to great physiological load during chewing, primarily due to its viscosity, consistency, low modulus of elasticity and ease of handling (1).

Compositions with low filler content and modulus of elasticity have shown better sealing ability in Class V restorations as compared to composites with high filler content. It is generally accepted that the use of materials with low modulus of elasticity reduces cervical cracks and microleakage (2). They are also used as a liner under composites of normal viscosity, small class I and class $\mathrm{V}$ cavities, as sealants, and to restore defects in damaged ceramic restorations (3).

An innovative resin based material with self-adhesive characteristics, Vertise Flow, which introduced a new category of restorative material called "self-etch flowable composites", has recently been developed. Self-etch flowable composites combine properties of composites and self-etch adhesives, eliminating the need for separate bond application that simplifies direct restorative procedure. Therefore, Vertise Flow represents 8th generation of dentin adhesive systems.

Benefits of self-etch flowable composites vs. traditional composites are simple and fast application, reduced postoperative sensitivity, better control, less chance of errors and good aesthetics $(4,5)$. Embedding a composite restoration in posterior teeth is generally a time-consuming activity. The techniques of layers and thin $2 \mathrm{~mm}$ polymerization increments of the composites are widely recommended (6). When extensive cavities are filled in posterior teeth, such a treatment can imply the risk of incorporating air bubbles or contaminants between the increments (7).

Manufacturers of composite materials, aiming to simplify the procedure of introducing the material into the cavity and its polymerization, currently offer bulk-fill type composite resins. Simplification of procedures and decreasing the time of embedding bulk-fill type restorations are due to the possibility of applying a single composite increment of up to $4 \mathrm{~mm}$.

Deeper penetration of light into these materials is enhanced by their high color translucency, however, if the cavity is deeper than the maximum depth of cure $4 \mathrm{~mm}$, it is necessary to apply another layer. The innovative system of polymerization initiation determines the decrease of light curing time and the increase of the depth of cure. Low shrinkage of these materials and their high filler content cause the polymerization shrinkage stresses to be very low and this allows the application of thicker layers. The color matching process is faster due to the universal color of the materials. Moreover, it was noticed that the finishing and polishing of the restoration required less time $(8,9)$. 
The aim of this study is to evaluate and compare the microleakage and shear bond strength of Self-adhesive and Bulk fill flowable composite resins.

\section{MATERIALS AND METHODS}

Forty freshly extracted human molars were collected to be used in this study. The teeth used in this study were extracted for periodontal reasons. They were free from caries, visible cracks, cervical abrasion or any structural defects. Immediately after extraction, the molars were washed under running water to remove blood and mucous, they were then cleaned with ultrasonic scaler to remove calculus and remnants of soft tissues and finally polished with polishing paste and brush mounted on low speed hand piece (10). After examination, the molars were disinfected in a $0.5 \%$ Chloramine $\mathrm{T}$ solution for one week and subsequently stored in distilled water which was changed weekly for two months' till being experimented (11).

\section{I-Microleakage test}

\section{A-Specimen preparation}

Twenty molars were used in this test. To prepare a standardized class $\mathrm{V}$ cavity with dimensions of approximately (4 mm mesiodistal, $3 \mathrm{~mm}$ occlusogingivally and $2 \mathrm{~mm}$ in depth), a tofflemire metal band with window of (4 mm mesiodistal, $3 \mathrm{~mm}$ occlusogingivally) was held around the tooth by a tofflemire retainer adapted $1 \mathrm{~mm}$ above the cervical line on the labial surface of the extracted teeth. In order to standardize the cavity depth, a mark (using water resistance marker) was done on the bur with a premeasured depth of $2 \mathrm{~mm}$. The preparation was performed by using 0.8 straight fissure bur (Komet, Lemgo, Germany) mounted on a high speed handpiece under copious water cooling (12). Cavities were lightly dried.

The teeth were randomly divided into 2 groups:

Group I: 10 Specimens were used. The surfaces of the cavity were gently brushed using single bond universal adhesive for 20 second using the disposable applicator. Gentle burst of air drying to the adhesive for 5 seconds was done, followed by curing for 10 seconds. Filtek flowable bulk fill composite was dispensed. As the material extruded, the tip was slowly raised. The cavity was filled in one bulk technique. The restoration was adapted by a transparent Mylar matrix and cured for 40 seconds (Halogen Curing Light, $3 \mathrm{M}, \mathrm{MN}$, USA). The restorations were finished using soflex contouring and finishing $\operatorname{discs}(3 \mathrm{M}, \mathrm{MN}, \mathrm{USA})$.

Group II: 10 Specimens were used. The surfaces of the cavity were gently brushed with $1 \mathrm{~mm}$ thickness Vertise flow for 20 seconds using the disposable applicator then, it was cured for 40 seconds. Vertise flow was dispensed. As the material was extruded, the tip was slowly raised to minimize air entrapment. The cavity was filled by $1 \mathrm{~mm}$ increments. The restoration was adapted by a transparent Mylar matrix and cured for 40 seconds. The restorations were finished using soflex contouring and finishing discs. The specimens were stored in distilled water at $37^{\circ} \mathrm{C}$ for one week, and thermocycled for 500 cycles between $5 \pm 2^{\circ} \mathrm{c}$ and $55 \pm 2^{\circ} \mathrm{c}$ with a 30 second dwell time and a transfer time of 10 seconds (13). Table 1 shows the materials used in this study

\section{B-Microleakage testing}

The root apices of teeth were sealed with sticky wax. All external surfaces were covered with two layers of nail varnish using a brush except for the surface of the restoration and $1 \mathrm{~mm}$ beyond its margins. The teeth were immersed in a $0.5 \%$ basic fuchsine dye ${ }^{*}$ solution for 24 hours at room temperature (14). The teeth were sectioned longitudinally in a bucco-lingual direction through the center of the restoration using a diamond disc under water spray (Fig.1).

Table (1): showing the used restorative materials.

\begin{tabular}{|c|c|c|c|}
\hline Material & Type & Manufacturer & Composition \\
\hline $\begin{array}{c}\text { Filtek } \\
\text { Bulk fill } \\
\text { flowable } \\
\text { composite }\end{array}$ & $\begin{array}{l}\text { Nano filled } \\
\text { flowable } \\
\text { bulk fill } \\
\text { composite }\end{array}$ & $\begin{array}{l}\text { 3M - ESPE } \\
\text { Dental } \\
\text { Products, St } \\
\text { Paul, MN, } \\
\text { USA }\end{array}$ & $\begin{array}{c}\text { Matrix: bisGMA, UDMA, } \\
\text { bisEMA and Procrylat } \\
\text { resins. } \\
\text { Filler: zirconia, silica } \\
\text { fillers } 0.01-3.5 \mu \text {, ytterbium } \\
\text { trifluoride fillers } 0.1-5.0 \mu \text {. } \\
\text { Filler content: } 64.5 \% \text { wt } \\
\quad / 42.5 \% \text { vol. }\end{array}$ \\
\hline $\begin{array}{l}\text { single } \\
\text { bond } \\
\text { universal } \\
\text { adhesive }\end{array}$ & $\begin{array}{l}\text { One } \\
\text { component, } \\
\text { combine } \\
\text { Self-Etch } \\
\text { and Total- } \\
\text { Etch. } \\
\end{array}$ & $\begin{array}{c}3 \mathrm{M}-\mathrm{ESPE} \\
\text { Dental } \\
\text { Products, St } \\
\text { Paul, MN, } \\
\text { USA }\end{array}$ & $\begin{array}{l}10 \text { MDP Phosphate } \\
\text { monomer, Dimethacrylate } \\
\text { resins, HEMA, } \\
\text { VitrebondCopolymer,Filler, } \\
\text { Ethanol, Silane, Initiators. }\end{array}$ \\
\hline $\begin{array}{c}\text { Vertise } \\
\text { flow }\end{array}$ & $\begin{array}{c}\text { Self- } \\
\text { adhesive } \\
\text { flowable } \\
\text { composite }\end{array}$ & $\begin{array}{c}\text { Kerr } \\
\text { corporation, } \\
\text { orange, CA, } \\
\text { USA }\end{array}$ & 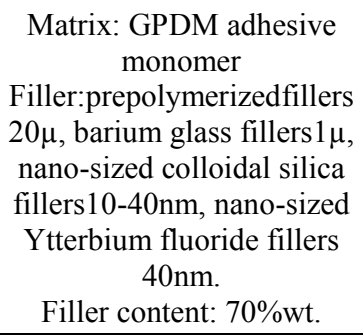 \\
\hline
\end{tabular}

The degree of dye penetration in the enamel and dentin cavity walls was assessed separately under a stereomicroscope (Olympus, Tokyo, Japan) at $40 \times$ magnification.

Six-point leakage scoring system was used to assess the extent of dye penetration at the dentine and enamel walls (Fig. 2) (15):

$\mathbf{0}=$ No microleakage.

$\mathbf{1}=$ Leakage up to enamel dentin junction or depth of $0.5 \mathrm{~mm}$ on the lateral wall.

$\mathbf{2}=$ Leakage up to the half of the lateral wall

(Leakage depth up to $0.5 \mathrm{~mm}$ ).

$3=$ Leakage over the half of the lateral wall

(Leakage depth between $0.5 \mathrm{~mm}$ and $1 \mathrm{~mm}$ ).

$\mathbf{4}=$ Subtotal leakage on the whole of the lateral wall (Leakage depth $=2 \mathrm{~mm}$ ).

$\mathbf{5}=$ Total leakage partly or entirely over the pulpal wall of the cavity (leakage depth more than $2 \mathrm{~mm}$ ).

The results of microleakage test were obtained by Wilcoxon signed ranks test for comparing between occlusal and cervical margins of both restorations. And, Mann Whitney test for comparing between two studied groups in Occlusal and cervical margins individually.

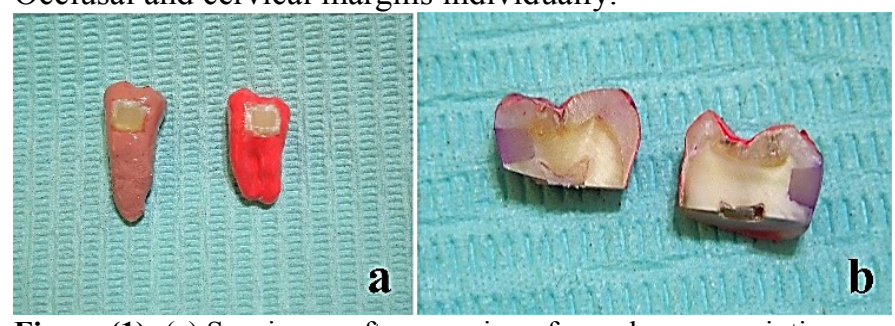

Figure (1): (a) Specimens after covering of apex by wax, painting with two layers of nail varnish. (b)buccolingual cutting of the tooth. 


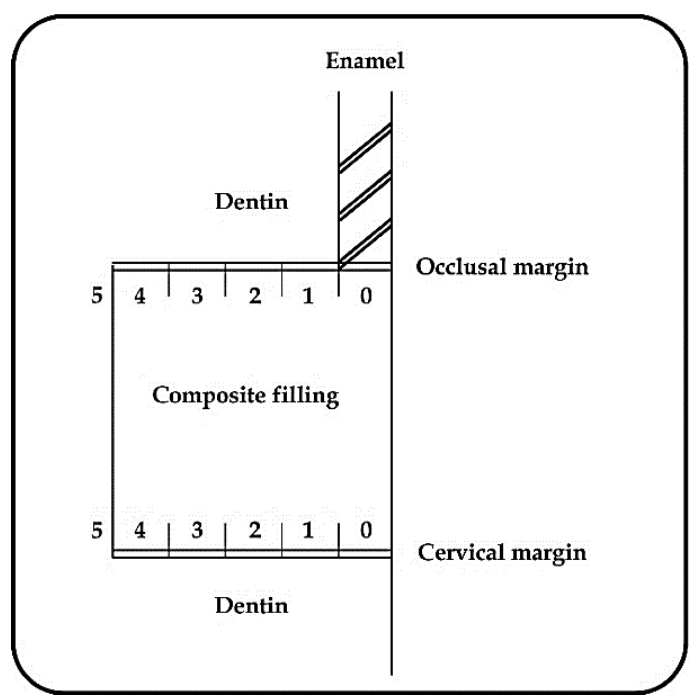

Figure (2): Illustration of the 6-point severity scale used to evaluate the microleakage at the margins of the restorations (occlusal and cervical margins).

\section{II-Shear bond strength test}

\section{A-Specimen preparation}

Twenty molars were used in this test. In order to facilitate manipulation, each tooth was embedded in chemically cured acrylic resin inside metal molds with $20 \mathrm{~mm}$ height and $15 \mathrm{~mm}$ diameter. The occlusal surfaces of the teeth were reduced by a low speed diamond disk. This produced sufficiently large flat dentine surface flushed with the mold and perpendicular on the specimen base (Fig. 3a). In order to ensure a standardized bonding area on the target surfaces a cylindrical shaped plastic matrix with $4 \mathrm{~mm}$ internal diameter and $3 \mathrm{~mm}$ height was used (16). Specimens were divided into 2 groups of 10 specimens each according to the material to be tested.

Group I: 10 Specimens were used. The flat dentine surface was gently brushed with single bond universal adhesive for 20 second using the disposable applicator. Gentle air drying was done for 5 seconds followed by curing for $10 \mathrm{sec}$. Filtek flowable bulk fill composite was dispensed at the deepest part of the cylindrical shaped plastic matrix. The matrix was filled in one bulk technique. The restoration was cured for 40 seconds.

Group II: 10 Specimens were used. The flat dentine surface was gently brushed with Vertise flow for 20 second using the disposable applicator then cured for $40 \mathrm{sec}$. Vertise flow was dispensed at the deepest part of the cylindrical shaped plastic matrix (with $4 \mathrm{~mm}$ internal diameter and $3 \mathrm{~mm}$ height) keeping the tip close to cavity floor. The cavity was filled by $1 \mathrm{~mm}$ increments.

The restoration was cured for 40 seconds.

Specimens were stored in distilled water at $37^{\circ} \mathrm{C}$ for one week, and then they subjected to thermocycling for 500 cycles between $5 \pm 2{ }^{\circ} \mathrm{c}$ and $55 \pm 2{ }^{\circ} \mathrm{c}$ with a 30 second dwell time and a transfer time of 10 seconds.

\section{b - Shear bond strength testing}

All specimens were secured in a specially designed holder to a universal testing machine (Maxitorq,Com-Ten Industries, Florida, USA). Shear load was directed parallel to the bonded interface at cross head speed of $1 \mathrm{~mm} /$ minute and the loading performed until fracture occurred (Fig. 3b), as manifested by the de-bonding of the composite cylinder (17).
The shear bond strength was calculated by the following equation: Shear bond strength in $(\mathrm{MPa})=$ the maximum failure load recorded in Newtons $(\mathrm{N}) /$ surface area of the bonded interface $\left(\mathrm{mm}^{2}\right)$ Area $\left(A=\pi r^{2}\right)$. The results of shear bond strength test were obtained by student $\mathrm{t}$ - test for comparing between two studied groups.

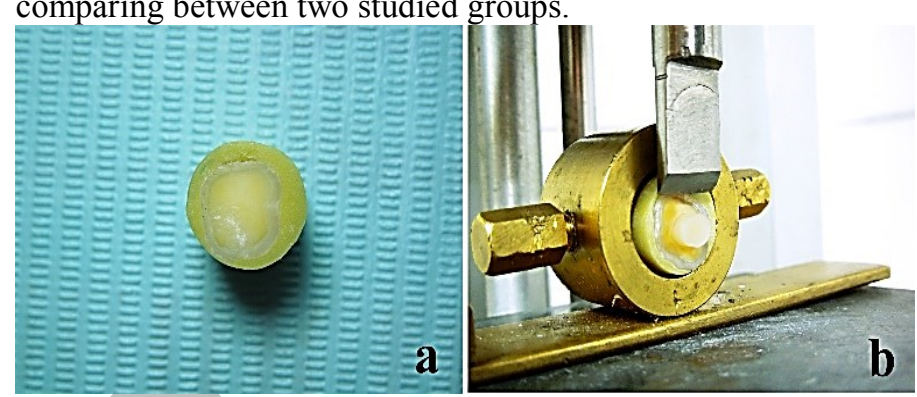

Figure (3): (a) Specimen of shear bond strength test, (b) Shear bond strength testing.

\section{RESULTS}

\section{Microleakage test}

The results of microleakage test showed that, the cervical margins showed higher mean of microleakage scores than occlusal margins in the two studied restorative materials (Fig. 4). However, these differences were not statistically significant by Wilcoxon signed ranks test with $(\mathrm{p} \geq 0.05)$ .Filtek flowable bulk fill composite showed significantly higher mean of microleakage scores than Vertise flow by Mann Whitney test with $(\mathrm{p} \leq 0.05)$ at both the occlusal and cervical margins (Table 2 ).

Table (2): Scores of microleakage of the two studied restorative materials at the occlusal and cervical margins.

\begin{tabular}{|c|c|c|c|c|}
\hline & \multicolumn{2}{|c|}{$\begin{array}{c}\text { Filtekflowablebulkfill } \\
\text { composite }\end{array}$} & \multicolumn{2}{|c|}{ Vertise flow } \\
\hline & Occlusal & Cervical & Occlusal & Cervical \\
\hline Min. & 0.0 & 0.0 & 0.0 & 0.0 \\
\hline Max & 4.0 & 5.0 & 2.0 & 2.0 \\
\hline Mean & 1.70 & 2.30 & 0.60 & 0.70 \\
\hline SD. & 1.16 & 1.49 & 0.70 & 0.67 \\
\hline Median & 1.50 & 2.0 & 0.50 & 1.0 \\
\hline$Z_{1}(p)$ & \multicolumn{2}{|c|}{$1.473(0.141)$} & \multicolumn{2}{|c|}{$0.250(0.803)$} \\
\hline$Z_{2}(\mathbf{p})$ & & & $\begin{array}{c}2.307^{*} \\
\left(0.021^{*}\right)\end{array}$ & $\begin{array}{c}2.619^{*} \\
\left(0.009^{*}\right)\end{array}$ \\
\hline
\end{tabular}

$\mathrm{Z}_{1}: \mathrm{Z}$ for Wilcoxon signed ranks test for comparing between Occlusal and Cervical

$\mathrm{Z}_{2}: \mathrm{Z}$ for Mann Whitney test for comparing between two studied groups in Occlusal and Cervical

*: Statistically significant at $\mathrm{p} \leq 0.05$

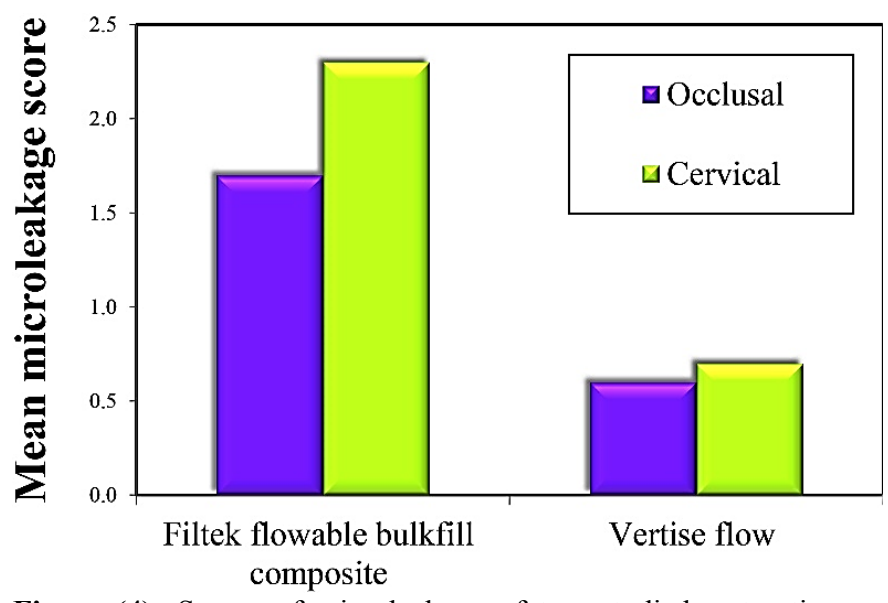

Figure (4): Scores of microleakage of two studied restorative materials at the occlusal and cervical margins. 


\section{Shear bond strength test}

The results of shear bond strength test showed that, Filtek flowable bulk fill composite showed significantly higher mean of shear bond strength than Vertise flow (Fig.5) by student t-test $(\mathrm{p} \leq 0.05)$ (Table 3$)$.

Table (3): Scores of shear bond strength of two studied restorative materials in megapascals.

\begin{tabular}{||c|c|c||}
\hline & $\begin{array}{c}\text { Filtekflowablebulkfill } \\
\text { composite (MPa) }\end{array}$ & Vertise flow (MPa) \\
\hline Min. & 18.0 & 17.0 \\
Max & 25.0 & 22.0 \\
Mean & 21.70 & 19.10 \\
SD. & 2.54 & 1.79 \\
Median & 21.0 & 19.0 \\
\hline $\mathbf{t}(\mathbf{p})$ & \multicolumn{2}{|c|}{$2.644^{*}\left(0.016^{*}\right)$} \\
\hline
\end{tabular}

t: Student t-test

*: Statistically significant at $\mathrm{p} \leq 0.05$

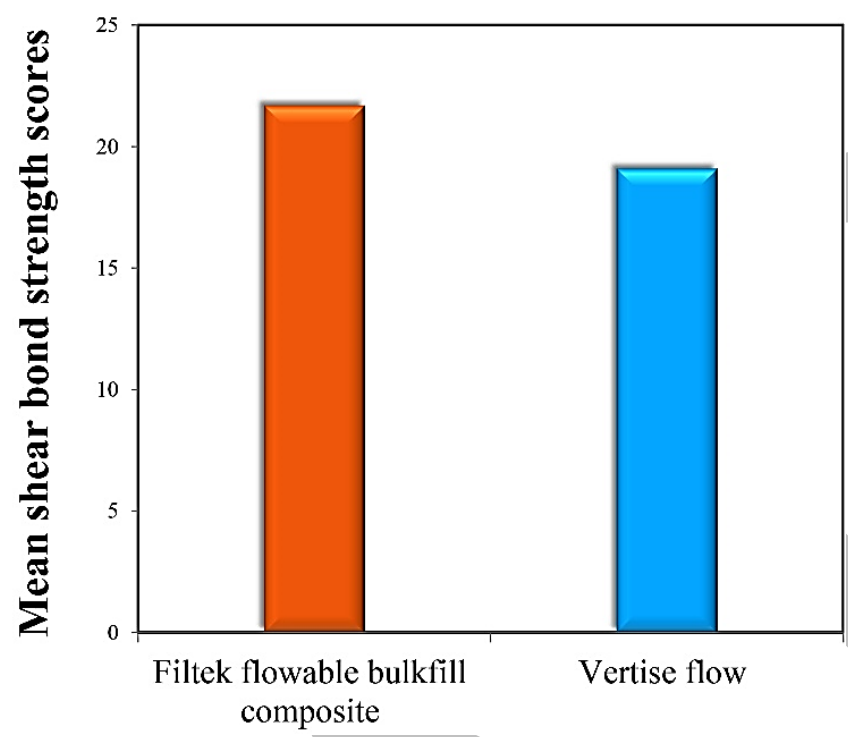

Figure (5): Scores of shear bond strength of two studied restorative materials in megapascals.

\section{DISCUSSION}

\section{Microleakage test}

The results obtained from this study showed that the two restorative materials used exhibited more microleakage on the cervical margins than on the occlusal margins. This is because the cervical margin has less thickness of enamel layer than occlusal margin. Also, there are other reasons such as the difference of the organic nature of dentine substrate between occlusal and cervical margins, different histological structure between occlusal and cervical margins and less hydroxyapatite crystals at the cervical margins (18).

In the current study, the single increment application and polymerization method (the bulk-fill technique) proposed by the manufacturers of these composites did not compromise marginal adaptation of restorations. On the other hand, Abbas et al. and Federlin et al. obtained a lower degree of dye penetration in fillings made with layering technique than with one increment technique (19). The incremental technique has been largely recommended because it is expected to decrease the $\mathrm{C}$-factor. A technique that uses a large number of small, thin increments is normally considered the most appropriate placement technique to prevent excessive stress generation (20).
The current study confirmed that self-etch flowable composite materials has lower microleakage scores than Filtek flowable bulk fill composite.

Better marginal seal can be explained by the fact that Vertise Flow does not require additional step for adhesion. Moreover, micromechanical bond as result of intermingling of polymerized monomers of Vertise Flow and dentine collagen fibers also contributes to adhesion.

These results are in consistent with the results obtained by Janković $\mathrm{O}$ et al (2014) who found that Vertise Flow showed better quality of bond with hard dental tissue than Tetric Flow when classical polymerization technique was used (21). And, Campos EA et al (2014) who found that bulk-fill materials do not allow better marginal adaptation than a standard composite(22).Besides, Abu El Naga A et al (2015) found that, the self-adhesive flowable composite provided better sealing ability (23).In addition to that, Vichi A et al (2013) found that Vertise flow resulted in lower bond strengths values on either dental substrate, better marginal sealing ability was visualized in comparison with all-in-one adhesive systems(24).

None of the two restorative materials that were investigated was able to completely eliminate microleakage. This might be attributed to the difference in coefficient of thermal expansion, polymerization shrinkage, cavity configuration, light polymerization concepts and units, lack of adhesion between the restorative material and dentin, lack of adaptation of the restoration to the cavity wall and improper manipulation of materials.

\section{Shear bond strength test}

When shear bond strength to dentin was evaluated, Vertise flow recorded significantly lower shear bond strength than Filtek bulk fill flowable composite with single bond universal. This may be due to the non-homogenous adhesive layer in Vertise flow group which might explain its low bond strength.

Also the low dentin wettability of Vertise flow did not allow an intimate contact between the material and dentin structure and consequently chemical interaction was limited.

As a matter of fact, the viscosity of Vertise Flow is considerably higher than that of single bond universal with Filtek flowable bulk fill composite. Single bond universal which is the main cause of adhesion of Filtek flowable bulk fill makes deeper penetration and more wetting to the dentine substrate than Vertise flow which works superficially $(25,26)$.Even though the first $0.5 \mathrm{~mm}$-thick layer of Vertise Flow was brushed with moderate pressure on the substrate for 15-20 seconds, this action did not provide shear bond strength to dentin as compared to the other group (27).

Besides, 10 - methacryloyloxydecyl dihydrogen phosphate (10-MDP) monomer is one of the most commonly used functional monomers. It is present in single bond universal. The stronger adhesion capability of flowable bulk fill composite is also due to this component. It is reported to be the most promising monomer for chemical bonding to hydroxyapatite of enamel and dentin due to its stability against hydrolysis and forming strong ionic bonds with calcium (28). It is a hydrophilic phosphate monomer that increases resin diffusion and adhesion by causing acidic decalcification and binding to calcium ions or amino groups of tooth structure. It is reported to be one 
of the most successful materials in the market for chemical bonding (29).

The Technical Bulletin Kerr/ 34929B (2010) shows that the Vertise flow is based on the bonding technology that uses GPDM (glycerol phosphate di methacrylate) adhesive monomer. GPDM monomers ensure a tenacious bond to both enamel and dentin. GPDM adhesive monomer acts like a coupling agent (Fig. 6). On one hand, it has an acidic phosphate group for etching the tooth structure and also for chemically bonding to the calcium ions within the tooth structure. On the other hand, it has two methacrylate functional groups for co-polymerization with other methacrylate monomers to provide increased cross linking density and enhanced mechanical strength for the polymerized adhesive. It is indicated that GPDM monomer etches rather than bonds to hydroxyapatite (30).

This result is in consistence with the result obtained by Tuloglu N et al (2014) who found that shear bond strength values of Vertise flow were lower than those for conventional flowable composite resins with one step selfetch adhesive (26). Furthermore, Ilie N et al (2014) found that bulk fill materials have higher shear bond strength than other groups of composite resins (31).

\section{GPDM Adhesive Monomer}

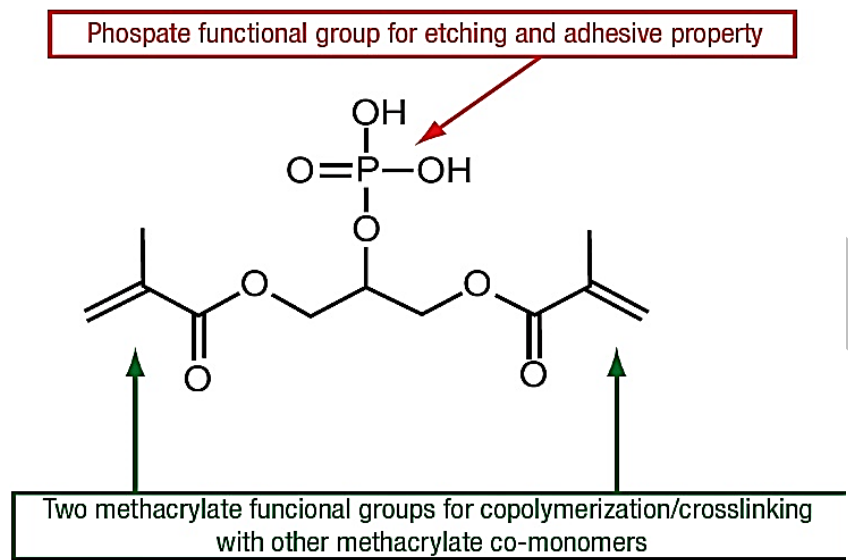

Figure (6): Role of GPDM adhesive monomer as a coupling agent.

\section{CONCLUSIONS}

Within the limitations of the present study it may be concluded that:

1) All of the restorative materials used were unable to prevent microleakage.

2) Vertise flow showed less microleakage than Filtek flowable bulk fill composite with single bond universal.

3) Vertise flow may be a suitable restorative material for restoring class $\mathrm{V}$ cavities with cervical margins existing below cement-enamel junction as it showed the least microleakage.

4) Filtek flowable bulk fill composite with single bond universal showed higher shear bond strength than Vertise flow.

\section{ACKNOWLEDGMENT}

I would like to thank Eman Gouda for her continuous support during conduction of this study.

\section{CONFLICT OF INTEREST}

The authors declare that they have no conflict of interest.

\section{REFERENCES}

1. Tarle Z, Attin T, Marovic D. Influence of irradiation time on subsurface degree of conversion and microhardness of high-viscosity bulk-fill resin composites. Clin Oral Investig 2015; 19: 831-40.

2. Peutzfeldt A, Asmussen E. Determinants of in vitro gap formation of resin composites. J Dent 2004; 32: 109-15.

3. Masao I, Hatanaka K, Suzuki K. Class V and flowable resin. Dent Mater 2006; 22: 875-83.

4. Deb S, Sehmi H. A comparative study of the properties of dental resin composites polymerized with plasma and halogen light. Dent Mater 2003; 19: 517-22.

5. Salerno M, Derchi G, Thorat S. Surface morfology and mechanical properties of new generation flowable resin composites for dental restorations. Dent Mater 2011; 27: 1221-8.

6. Wei Y, Silikas N, Zhang Z. Hygroscopic dimensional changes of self-adhering and new resin-matrix composites during watter sorption/desorption cycles. Dent Mater 2011; 27: 259-66.

7. Nagpal R, Manuja N, Tyagi S. In vitro bonding effectiveness of self-etch adhesives with different application techniques: a microleakage and scanning electron microscopic study. J Conserv Dent 2011; 14: 258-63.

8. Cenci M, Demarco F, Carvalho R. Class II composite resin restorationswith two polymerization techniques: relationship between microtensile bond strength and marginal leakage. J Dent 2005; 33: 603-10.

9. Deb S, Di Silvio L, Mackler EH, Millar JB. Pre warming of dental composites. Dent Mater 2011; 27: 851-9.

10. Moorthy A, Hogg CH, Dowling AH, Grufferty BF, Benetti AR, Fleming GJ. Cuspal deflection and microleakage in premolar teeth restored with bulk fill flowable resin based composite base materials. J Dent 2012; 40: 500-5.

11. Reena RK, Gill S, Miglani A. Storage media: A Neglected Variable for in Vitro Studies. J Ind Ortho Soc 2011; 45 : 5-8.

12. Kucukesmen C, Sonmez H. Microleakage of class V composite restorations with different bonding systems on florosed teeth. Eur J Dent 2008; 2: 48-58.

13. Cao L, Geerts S, Gueders A, Albert A, Seidel L, Charpentier J. Experimental comparison of cavity sealing ability of five dental adhesive systems after thermocycling. J Adhes Dent 2003; 5: 139-44.

14. Benedetti M, Webber F, Costa GM. Bulkfillresine based composite:Microleakage of class II restorations. J Surg Clin Dent 2014; 2: 15-9.

15. Eunice C, Margarida A, João CL, Filomena B. $99 \mathrm{mTc}$ in the evaluation of microleakage of composite resin restorations with SonicFill ${ }^{\mathrm{TM}}$. An in vitro experimental model. Open J Stomatology 2012; 2: 340-7.

16. Juloski J, Goracii C, Rengo C, Giovannetti A, Vichi A, Vulicevic ZR, et al. Enamel and dentine bond strength of new simplified two adhesive materials with and without preliminary phosphoric acid-etching. Am J Dent 2012; 25: 239-43.

17. Sharmer V, Rampal P, Kumar S. Shear bond strength of composite resin to dentine after application of cavity disinfectants. Contemp Clin Dent 2011; 2: 155-9.

18. Soldo M, Simeon P, Matijevic J, Glavina D, Illes D, Kramek SJ. Marginal leakage of class V cavities restored 
with silorane-based and methacrylate-based resin systems. Dent Mater J 2013; 32: 853-8.

19. Abbas G, Fleming G, Harrington E, Shortall A. Cuspal movement and microleakage in premolar teeth restored with a packable composite cured in bulk or in increments. J Dent 2003; 31: 437-44.

20. Ferracane JL. Buonocore lecture. Placing dental composites - a stressful experience. Oper Dent 2008; 33 : 247-57.

21. Janković O, Arbutina A, Knežević N, Arbutina R. Microleakage of Class V Cavities Restored with Flowable Composite Materials. Serbian Dent J 2014; 61: 314-7.

22. Campos EA, Ardu S, Lefever D, Jassé FF, Bortolotto T, Krejci I. Marginal adaptation of class II cavities restored with bulk-fill composites. J Dent 2014; 2: 2-7.

23. Aboelnaga A, Yousef $M$, Ramadan R, Bahgat SF, Alshawwa L. Does the use of a novel self-adhesive flowable composite reduce nanoleakage? Clin Cosmet Investig Dent 2015; 7: 55-64.

24. Vichi A, Margvelashvili M, Goracci C, Papacchini F, Ferrari M. Bonding and sealing ability of a new selfadhering flowable composite resin in class I restorations. Clin oral Investing 2013; 17: 1497-506.

25. Fu J, Kakuda S, Pan F, Hoshika S, Ting S, Fukuoka A, et al. Bonding performance of a newly developed step-less all-in-one system on dentin. Dent Mater J 2013, 32: 203 11.

26. Tuloglu N, Tunc ES, Ozer S, Bayrak S. Shear bond strength of self-adhering flowable composite on dentin with and without application of an adhesive system. J Appl Biomater Funct Mater 2014; 12: 97-101.

27. Brackett WW, Tay FR, Looney SW, Ito S, Haisch LD, Pashley DH. Microtensile dentin and enamel bond strengths of recent self-etching resins. Oper Dent 2008; 33: 89-95.

28. Wang T, Nikaido T, Nakabayashi N. Photocure bonding agent containing phosphoric methacrylate. Dent Mater 1991; 7: 59-62.

29. Watanabe I, Nakabayashi N, Pashley DH. Bonding to ground dentin by a pheny 1-P self-etching primer. J Dent Res 1994; 73: 1212-20.

30. Yoshida Y, Nagakane K, Fukuda R, Nakayama Y, Okazaki M, Shintani H, et al. Comparative study on adhesive performance of functional monomers. J Dent Res 2004; 83: 454-58.

31. Ilie N, Schöner C, Bücher K. An in-vitro assessment of the shear bond strength of bulk-fill resin composites to permanent and deciduous teeth. J Dent 2014; 42: 850-5. 